\title{
Energy consumption of auxiliary systems of electric cars
}

\author{
Ivan Evtimov ${ }^{1, *}$, Rosen Ivanov $^{1}$, and Milen Sapundjiev ${ }^{2}$ \\ ${ }^{1}$ University of Ruse, Department of Engines and Vehicles, Rousse, Bulgaria \\ ${ }^{2}$ University of Ruse, Branch Silistra, Bulgaria
}

\begin{abstract}
The paper analyzes the power demand of the auxiliary systems of electric cars. On the basis of existing electric cars an analysis of energy consumption of different auxiliary systems is done. As a result possibilities for rational use of these systems have been proposed, which can increase the mileage per one charge of the battery.
\end{abstract}

\section{Introduction}

An important characteristic of energy performance of the electric car is the distance covered for one charge of the battery [1-3]. Usually, in the technical specification of electric cars, producers give an operational range which is not precisely detailed about the conditions of motion (in city or inter-city traffic, air temperature, use of the auxiliary systems, etc.). For the owners it is very important to know as best as possible the remaining travel distance and impact of auxiliary systems on energy consumption and distance [4-7]. That knowledge will ensure a calm and comfortable trip regardless of the limited energy autonomy of electric cars.

The goal of the paper is to analyze the impact of different auxiliary systems of electric cars on the travel distance in different running conditions and comfort (such as temperature in the car, using lights, audio system, etc.).

\section{Exposition}

\subsection{Fundamentals of electric car energy consumption}

The main purpose of the energy accumulated in the battery is to supply the electric motor and to ensure the electric car motion in different running conditions. In addition, the battery also has to supply the auxiliary systems, which guarantee safety (lights, horn, window cleaner etc.) and comfort (climate control, media etc.). During the trip, the value of the specific energy consumption (in $\mathrm{Wh} / \mathrm{km}$ or $\mathrm{kWh} / 100 \mathrm{~km}$ ) can be different. Depending on the skills and needs of the driver, energy consumption can be 2 times higher than the one indicated in the technical specification of the electric car.

In the general case, the specific energy consumption can be determined theoretically by following the equation

$$
E_{100}=\frac{100}{3,6 \eta_{M} \eta_{E}}\left[\left(f_{o}+5.10^{-7} V^{2}\right) G+k_{B} S \frac{V^{2}}{13}\right]+E_{A S_{100}}, \frac{\mathrm{kWh}}{100 \mathrm{~km}}
$$

where $f_{o}$ is the rolling resistance coefficient at low speed; $V$ - car speed, $\mathrm{km} / \mathrm{h} ; G$-car weight, $\mathrm{kN} ; k_{B}-$ coefficient of aerodynamic resistance, $\mathrm{kNs}^{2} / \mathrm{m}^{4} ; S$ - the front area of the car, $\mathrm{m}^{2} ; \eta_{M}$ - the efficiency coefficient of transmission; $\eta_{E}$ - the efficiency coefficient of the electric motor and power electronics; $E_{A S 100}$ - the specific energy consumption of auxiliary systems, $\mathrm{kWh} / 100 \mathrm{~km}$.

Coefficient $k_{B}$ is calculated as

$$
k_{B}=0,5 \cdot 10^{-3} \rho c_{x}, \mathrm{kN} \mathrm{s}^{2} / \mathrm{m}^{4},
$$

where $\rho$ is air density, $\mathrm{kg} / \mathrm{m}^{3} ; c_{x}-$ drag coefficient.

The change of the air temperature $t$ from +40 to -20 ${ }^{\circ} \mathrm{C}$ causes a change in its density from 1,127 to 1,395 $\mathrm{kg} / \mathrm{m}^{3}$ [8] and at high speed it can increase the energy consumption by over $10 \%$. The value of the air density can be evaluated with good accuracy (deviation of not more than $0,5 \%$ at low temperature) using the equation

$$
\rho=2 \cdot 10^{-5} t^{2}-0,0048 t+1,2926, \mathrm{~kg} / \mathrm{m}^{3} \text {. }
$$

Mechanical losses in the transmission vary within wide limits and depend on the electric motor load. The efficiency coefficient $\eta_{M}$ can be evaluated with good accuracy using the approach, proposed in [1]. The losses in the electric motor and power electronics $\eta_{E}$ also depend on the working conditions and load. The product of both coefficients varies between $90-95 \%$, but can decrease by $50 \%$ under some running conditions [9]. It is necessary to have the characteristics of the elements of electric drive, not only at nominal load (whose value is given in the technical specifications), but also at particular load. Some of the researchers assign these two types of losses to the so called drive train losses [3].

\footnotetext{
* Corresponding author: ievtimov@uni-ruse.bg
} 
Auxiliary systems have great impact on energy consumption- the second part $E_{A S 100}$ of equation (1). The approach for their assessment has to be very accurate, especially when the maximal power of these devices is in use, to ensure exact determination of travel distance.

The power supply of auxiliary systems is realized by the second (operational) battery at a voltage of $12 \mathrm{~V}$. It can be recharged from the traction battery through $\mathrm{DC} / \mathrm{DC}$ convertor. The losses during this transformation have to be taken into account by introducing a coefficient marked as $\eta_{D C}$. Finally, the specific consumption of the auxiliary systems can be represented as

$$
E_{A S_{100}}=\frac{1}{\eta_{D C}}\left(E_{C C}+E_{L}+E_{W C S}+E_{O S}\right), \frac{\mathrm{kWh}}{100 \mathrm{~km}}
$$

where $\eta_{D C}$ is the efficiency coefficient of the convertor between two batteries; $E_{C C}-$ the specific energy consumption of climate control system; $E_{L}$ - the specific energy consumption of lights and horn; $E_{W C S}$ - the specific energy consumption of windows cleaning system; $E_{O S}$ - the specific energy consumption of other systems as SRS, ABS, TC ESP, electric windows open system etc.

\subsection{Distribution of the total energy consumption of the electric car}

An analysis of the distribution of the total energy used can be done on the basis of an existing example. Fig. 1 presents a real picture of the energy consumption of the Tesla Roadster electric car with different values of the speed. The climate control does not work [3].

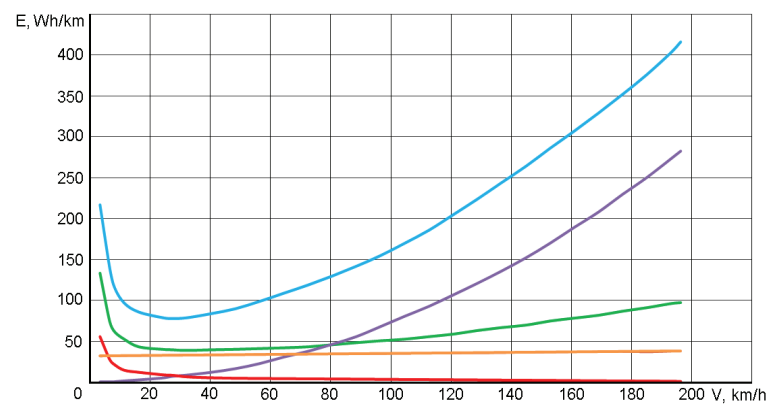

- total specific energy consumption; $\overline{-}-$ for drive train losses;
- - for air resistance;

Fig. 1. Distribution the total specific energy consumption of Tesla Roadster vs car speed

The ratio between the different parts of the total specific energy consumption changes with the increase of car speed. At low speed most significant is the part of energy consumption for drive train losses and supply of the auxiliary systems. Higher energy consumption in slow motion is caused by the low values of the efficiency coefficients $\eta_{M}$ and $\eta_{E}$. At high speed, the energy spent for air resistance becomes the largest.

The energy spent for rolling resistance is changed within short limits, because of the small impact of the speed on the coefficient $f$.
In fact, in motion the most variable parts of the energy can be those spent for air resistance and supply of auxiliary systems. The last part depends on the atmospheric conditions such as rain, snow, wind etc.

The curves shown in Fig.1 are well represented by the following regression models:

- total specific energy consumption

$$
\begin{aligned}
& E=4 \cdot 10^{-10} V^{6}-3 \cdot 10^{-7} V^{5}+7 \cdot 10^{-5} V^{4}- \\
& -0,009 V^{3}+0,5715 V^{2}-16,313 V+234,92
\end{aligned}
$$

- specific energy consumption for drive train losses

$$
\begin{aligned}
& E=3 \cdot 10^{-10} V^{6}-2 \cdot 10^{-7} V^{5}+5.10^{-5} V^{4}- \\
& -0,0057 V^{3}+0,358 V^{2}-10,26 V+139,27
\end{aligned}
$$

- specific energy consumption for rolling resistance

$$
E=0,0297 V+32,278 \text {; }
$$

- specific energy consumption for air resistance

$$
E=1.10^{-6} V^{3}+0,007 V^{2}+0,0035 V+86,22 ;
$$

- specific energy consumption for supply of auxiliary systems

$$
E=121,1 V^{-0,794}
$$

\subsection{Energy consumption of auxiliary systems}

Approximately, the energy consumption of the auxiliary systems presented as a percentage of the energy accumulated in the main (traction) battery is shown in Table $1[5,7]$.

Table 1. Energy consumption of some auxiliary systems

\begin{tabular}{|l|l|}
\hline Auxiliary systems & Part of traction battery energy, $\%$ \\
\hline $\begin{array}{c}\text { Climate control: } \\
\text { - cooling; } \\
\text { - heating. }\end{array}$ & $\begin{array}{l}\text { Up to } 30 \% \\
\text { Up to } 35 \%\end{array}$ \\
\hline Power steering & Up to $5 \%$ \\
\hline $\begin{array}{l}\text { Braking system } \\
\begin{array}{l}\text { Other (lights, media, } \\
\text { locks etc.) }\end{array}\end{array}$ & Up to $5 \%$ \\
\hline
\end{tabular}

The information presented in Table 1 is more general and does not include all operational conditions of electric cars. This is the reason to make a review of the impact different factors on energy consumption of each auxiliary system.

\section{Climate control system}

The normal internal temperature of the air in the compartment has to be $20-23{ }^{\circ} \mathrm{C}$. To maintain these limits, the energy consumption of climate control depends on the temperature difference in and out of the car. Table 2 presents an example of the needed power of control system at different internal temperatures and high external temperature [5]. 
Table 2. Needed power for supply of the climate control system as a function of internal temperature in the compartment

\begin{tabular}{|c|c|c|}
\hline $\begin{array}{c}\text { External air } \\
\text { temperature, }{ }^{\circ} \mathbf{C}\end{array}$ & $\begin{array}{c}\text { Internal } \\
\text { temperature, }{ }^{\circ} \mathbf{C}\end{array}$ & $\begin{array}{c}\text { Needed } \\
\text { power, } \mathbf{k W}\end{array}$ \\
\hline 43 & 21 & $1,5-2$ \\
\hline 43 & 25 & 1 \\
\hline 43 & 29 & 0,5 \\
\hline
\end{tabular}

The maximum value of the power supply of climate control can achieve $3-5 \mathrm{~kW}$ for some models of car. As heat device they use an electric heater or a thermo pump. In Fig. 2 the impact of power consumption of $2 \mathrm{~kW}$ (working climate control) on the travel distance is illustrated for Tesla Roadster electric car [3].

At a speed of $25 \mathrm{~km} / \mathrm{h}$, the travel distance per one charge of the battery decreases approximately 2 times when the climate control of $2 \mathrm{~kW}$ works. The curves are well represented by the following regression models: - travel distance without working climate control

$$
\begin{aligned}
& L=-9 \cdot 10^{-10} V^{6}+6 \cdot 10^{-7} V^{5}-0,0002 V^{4}+ \\
& +0,0228 V^{3}-1,6088 V^{2}+50,131 V+116,1
\end{aligned}
$$

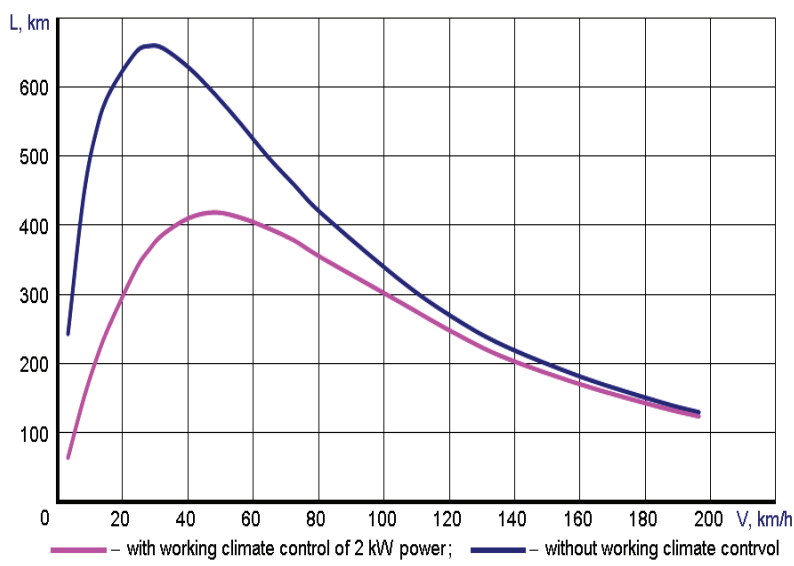

Fig 2. Impact of climate control power consumption of $2 \mathrm{~kW}$ on the distance per one charge of battery for Tesla Roadster electric car.

- travel distance with working climate control of $2 \mathrm{~kW}$ power

$$
\begin{aligned}
& L=-4 \cdot 10^{-6} V^{4}+0,0018 V^{3}-0,3157 V^{2}+ \\
& +19,881 V+10,837 .
\end{aligned}
$$

There is not much research on the impact of the external air temperature on energy consumption. In [10] a Canadian company, on the basis of over 7000 travels in the whole of North America, has made a generalization of the average energy consumption of Nissan Leaf electric car (Fig. 3).

The curve from Fig. 3 is well represented by the regression model

$$
\begin{aligned}
& E=8 \cdot 10^{-9} t^{6}-3 \cdot 10^{-6} t^{5}+0,0001 t^{4}+0,0028 t^{3}- \\
& -0,0546 t^{2}-2,7979 t+206,22 .
\end{aligned}
$$

The same data is shown in Fig.4 as impact on the travel distance L [11]. The respective regression model is

$$
\begin{aligned}
& L=6.10^{-8} t^{6}-4 \cdot 10^{-7} t^{5}-0,0001 t^{4}-0,0004 t^{3}+ \\
& +0,0544 t^{2}+1,3326 t+99,995
\end{aligned}
$$

It is obvious that the external air temperature has a significant impact on the energy consumption of an electric car. The explanation for this is connected with the energy for heating or cooling but also with the efficiency of the battery at different temperatures. Taking into account these two factors, one can see an optimal external air temperature at which the energy consumption is minimal and travel distance is maximal (Fig. 3, 4). This optimal value is approximately $20^{\circ} \mathrm{C}$.

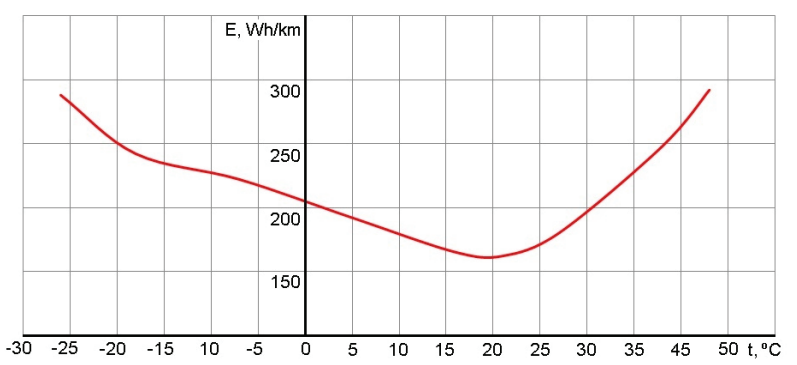

Fig. 3. Impact of the external air temperature on the specific energy consumption of a Nissan Leaf electric car.

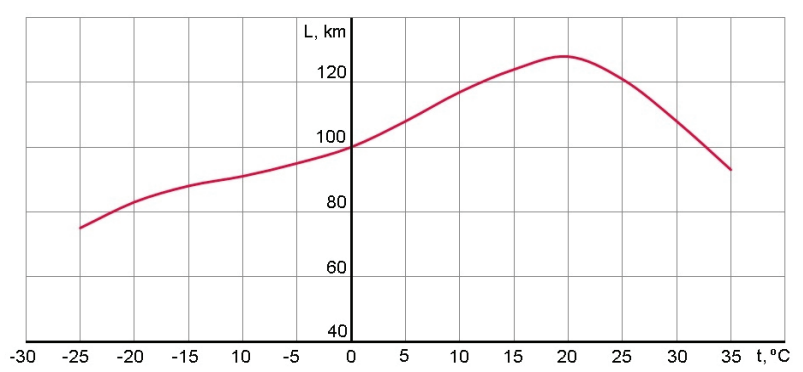

Fig. 4. Impact of the external air temperature on the travel distance of a Nissan Leaf electric car.

\section{Light system, light signalization and horn}

The energy consumption of the light system and signalization depend on a twenty-four-hour period - if the trip is realized in the day or at night. That is particularly important for long and short front lights. The usage of elements of light system and signalization, during $100 \mathrm{~km}$ travel, are presented in Table 3. The data from different sources [4, 6] was processed and summarized.

The calculations show that the maximal energy consumption of a light system using conventional lamps in night travel is about $150 \mathrm{Wh} / 100 \mathrm{~km}$. The usage of LED-lamps decreases the consumption $2,2-3,8$ times $[2,4,6,12,13]$.

In the specialized literature there is no information concerning the time of use and energy consumption of the horn. Probably, this is because the value of the energy used is insignificant. 
Table 3. Statistical data for the use of the elements of the light system and signalization.

\begin{tabular}{|l|c|c|c|}
\hline \multicolumn{1}{|c|}{ Elements } & $\begin{array}{c}\text { Working } \\
\text { time, } \\
\text { min/100 km }\end{array}$ & $\begin{array}{c}\text { Power } \\
\text { consumption } \\
\text { for car with } \\
\text { conventional } \\
\text { lamps, W }\end{array}$ & $\begin{array}{c}\text { Power } \\
\text { consumption } \\
\text { for electric car } \\
\text { with LED- } \\
\text { lamps, W }\end{array}$ \\
\hline Daily lights & 116,5 & 40 & 8 \\
\hline Long lights & $9,8^{*}$ & 60 & 34,4 \\
\hline Short lights & $97,6^{*}$ & 55 & 54 \\
\hline Left blinker & 5,8 & 21 & 6,9 \\
\hline Right blinker & 4,6 & 21 & 6,9 \\
\hline Stop-lights & 18,9 & 21 & 5,6 \\
\hline $\begin{array}{l}\text { Stop-lights } \\
\text { (central } \\
\text { position) }\end{array}$ & 18,9 & 21 & 3 \\
\hline Rear-lights & 107,4 & 5 & 1,7 \\
\hline $\begin{array}{l}\text { Registration } \\
\text { table lights }\end{array}$ & 107,4 & 5 & 0,5 \\
\hline $\begin{array}{l}\text { Reverse motion } \\
\text { light }\end{array}$ & 0,9 & 21 & 5,2 \\
\hline \multicolumn{4}{|l|}{$*$ night time driving only } \\
\hline
\end{tabular}

\section{Audio system}

Energy consumption depends on the power characteristic and the time the system is used. Usually, built-in systems have a power supply of about $200 \mathrm{~W}$. The time during which the audio system is used varies within wide limits and corresponds to the driver and passenger(s) needs.

The actual energy consumption also depends on the sound level. Some authors [9], in simulation models, give an average power supply of $20 \mathrm{~W}$ for the audio system and use a ratio of approximately $75 \%$ of travel time.

\section{Windows cleaning system and seat heating}

This system uses electric motors with maximum power of 30-50 W. The time of use strongly depends on the weather (if there is rainfall or snowfall).

The average consumption of the seat heating system is $30 \mathrm{~W}$ and the mean ratio of use $-5 \%$ of the time [9].

\section{Other systems}

The main systems included in this group are: the system of passive and active safety - SRS; Anti-lock Braking System - ABS; Traction Control System - TC; Dynamic Stability System - ESP; systems for opening and closing of door windows and roof. The biggest consumers in this group are the systems for active safety, but the value of energy depends on driving style.

\section{Internal losses in traction battery}

Depending on the battery type, during idle time (no traction) the additional losses can present for the maintenance of the working temperature. For example, natrium-nikelhidrid batteries work at a temperature of approximately $300{ }^{\circ} \mathrm{C}$ and permanent consumption power of $60-80 \mathrm{~W}$ for temperature maintenance. If the capacity of the battery is $18 \mathrm{kWh}$ after 10 days of idle time it will be fully discharged.

Internal losses of the Lithium-ion batteries depend on the number of the connected cells and Battery Management System - BMS.

Every battery has a limited period of exploitation. To extend that period the power electronics controls charge/discharge the process. This means that only part of the battery capacity can be used - full charge and discharge are unavailable. This is done to provide for the possibility of accumulation of the regenerative braking energy.

\subsection{Impact of regeneration on travel distance}

Regeneration of electric energy is possible during the braking process. Depending on the running conditions and route characteristics, the maximuml value of regenerative energy varies from 10 to $25 \%$ in city conditions $[14,15]$. The experimental results $[14,15]$ show that braking deceleration within the limits of $2-3$ $\mathrm{m} / \mathrm{s}^{2}$ can ensure efficiency of regenerative braking of up to $90 \%$ and minimal transformation of kinetic energy to heat and friction in mechanical braking system (Fig. 5).

At bigger decelerations, the battery cannot receive regenerative energy, the mechanical braking system is switched on and the two systems work together to provide the required deceleration (Fig. 6).

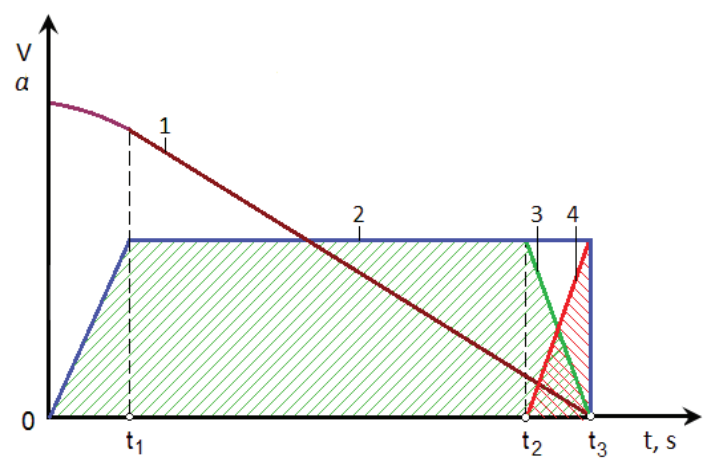

Fig. 5. Example of regenerative braking: 1 - car speed; 2, 3 - deceleration, realized only by regenerative braking; 4 - deceleration, realized only by mechanical braking system.

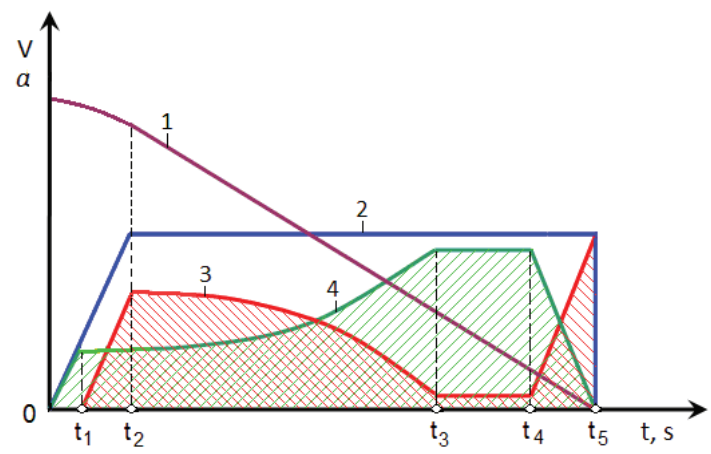

Fig. 6. Interaction of the two braking systems during formation of constant deceleration: 1 - car speed; 2 - total deceleration; 3 - deceleration, realized by mechanical braking system; 4 deceleration, realized by regenerative braking. 
To improve the usage of regenerative energy traction system super capacitors (especially in buses) are often build-in.

\section{Conclusions}

On the basis of the analysis of the impact of the running conditions and auxiliary systems on the energy consumption of an electric car, the following conclusions can be formulated:

1. The minimal energy consumption of electric cars is realized at lower speed - up to $40 \mathrm{~km} / \mathrm{h}$. These values are significantly lower than the respective ones for conventional cars - approximately $65 \mathrm{~km} / \mathrm{h}$.

2. At low speed, for example $5 \mathrm{~km} / \mathrm{h}$ (heavy traffic and jams), the energy consumption can be equal to that one at $100 \mathrm{~km} / \mathrm{h}$. The reason for this are the low efficiency of the drive train and energy consumption for supply of the auxiliary systems at low speed motion.

3. At high speed - over $50 \mathrm{~km} / \mathrm{h}$ - the impact of the auxiliary systems in total energy consumption decrease, the energy consumption spent for air resistance becomes dominant.

4. At some values of speed and weather conditions, the energy consumption for the supply of auxiliary systems can decrease twice travel distance of the car.

5. The minimal energy consumption of auxiliary systems is realized at an external air temperature of 20 ${ }^{\circ} \mathrm{C}$, at which the biggest travel distance is achieved.

6. The light system and signalization consume about $1 \%$ of total energy consumption of an electric car.

The authors would like to thank the Scientific Research Fund of the University of Ruse, Project 2017-FT-01 for the financial support.

\section{References}

1. R. Ivanov, I. Evtimov, M. Sapundjiev, A model for investigation of energy characteristic of an electric car, Electric vehicles EM 15, 131-137, (in Bulgarian), (2015)

2. E. Schaltz. Electrical Vehicle Design and Modeling, Electric Vehicles - Modelling and Simulations, 496, (2011)

3. EV Energy Consumption, www.solarjourneyusa.com/EVdistanceAnalysis5.php

4. B. Schoettle, M. Sivak, Y. Fujiyama. Leds and power consumption of exterior automotive lighting: implications for gasoline and electric vehicles. Report No. UMTRI-2008-48, 18 (2008)

5. EV Auxiliary Systems Impacts, http://avt.inl.gov/sites/default/files/pdf/fsev/auxiliary. pdf

6. M. Vražić, O. Barić, P. Virtič. Auxiliary systems consumption in electric vehicle. Przegląd elektrotechniczny, 12, 172-175 (2014)

7. A. Santiangeli, C. Fiori, F. Zuccari, A. Dell'Era, F. Orecchini, A. D'Orazio. Experimental analysis of the auxiliaries consumption in the energy balance of a pre-series plug-in hybrid-electric vehicle. Energy Procedia, 45, 779-788 (2014).

8. Air - Density and Specific Weight, http://www.engineeringtoolbox.com/air-densityspecific-weight-d_600.html

9. A. Duce, P. Egede, G. Öhlschläger, T. Dettmer, H. Althaus, T. Bütler, E. Szczechowicz, Guidelines for the LCA of electric vehicles, 158, http://www.elcarproject.eu/fileadmin/dokumente/Guideline_versions/ eLCAr_guidelines.pdf (2013)

10. Real-World Nissan LEAF Fleet Data Reveals, http://insideevs.com/real-world-nissan-leaf-fleetdata-reveals

11. Do electric cars work in cold weather? Get the Facts, http://blog.ucsusa.org/dave-reichmuth/electric-carscold-weather-temperatures

12. P. Mashkov, B. Gyoch. Thermal loading investigation of led bulbs for automotive headlights. SR RU\&SU, 55(4), 66-80, (in Bulgarian), (2016)

13. P. Mashkov, B. Gyoch, R. Ivanov, An investigation on characteristics of led bulbs for car headlights, BulTrans-2016, 118-123, (in Bulgarian), (2016)

14. I. Evtimov, R. Ivanov, G. Kadikyanov, Investigation of electric bicycle's regenerative braking, BulTrans2012, 217-221, (in Bulgarian) (2012)

15. D. Mammosser, M. Boisvert, P. Micheau, Designing regenerative braking strategies for electric vehicles with an efficiency map, $21^{\text {eme }}$ Congres Francais de Mecanique, 6 (2013) 